\title{
Energy consumption and heat recovery of an industrial fluidized catalytic cracking process based on cost savings
}

\author{
Aysar T. Jarullah ${ }^{1} \cdot$ Noor A. Awad ${ }^{1}$
}

Received: 1 August 2018 / Accepted: 6 November 2018 / Published online: 24 November 2018

(c) The Author(s) 2018

\begin{abstract}
Energy consumption is a significant issue in operation design for low-cost sustainable production and is accomplished by heat integration giving overall environmental advantages via reducing carbon emissions. Heat recovery is a beneficial tool that determines the minimum cooling and heating demand through recovery and re-use of energy within the process. Thus in this study, process of heat recovery and energy consumption of the fluidized catalytic cracking (FCC) is investigated to recover most of the external energy and reducing the environmental effect in addition to maximizing the productivity with minimum overall cost of the process. Where the performance of the FCC units plays a major role on the overall economics of refinery plants and improvement in operation or control of FCC units, it will result in dramatic economic benefits. The heat integration process is done based on experimental information from pilot scale, mathematical modeling developed and commercial process reported in our earlier study.
\end{abstract}

Keywords FCC $\cdot$ Heat integration $\cdot$ Energy consumption $\cdot$ Heat recovery $\cdot$ Cost savings

\section{Introduction}

One of the assignments with which chemical engineers constantly tend to be involved is scaling up of pilot plant tests to full-scale production. Because of the high operating cost of a pilot plant, this progression is beginning to be outperformed in different cases by generating the full-scale unit depending on the operation of a small-scale plant named a microplant. With a specific end goal making such manner effectively, an exhaustive comprehension of the chemical kinetics and transport restrictions is essential $[1,8]$. The evaluation of the optimal cooling and heating prerequisites (the minimum) uncover imperative energy savings. For example, Union Carbide in the United States of America and Imperial Chemical Industries in the United Kingdom have both detailed the consequences of various case examinations that reference $30-50 \%$ energy savings in contrast with traditional practice [5]. $\mathrm{CO}_{2}$ contents in the air have risen from 270 to $380 \mathrm{ppm}$ by 2006. The essential human source of $\mathrm{CO}_{2}$ in the air is generated by consuming petroleum derivatives

Aysar T. Jarullah

A.T.Jarullah@tu.edu.iq

1 Chemical Engineering Department, College of Engineering, Tikrit University, Tikrit, Iraq towards energy generation and transportation opportunities. To keep away from or lessen global warming, an important concentration in all $\mathrm{CO}_{2}$ emissions should be accomplished (25\%- $40 \%$ by 1990 and $80 \%-95 \%$ by 2050 ) [6, 8]. Nevertheless, more productive usage of energy consumption reduces the negative effects of $\mathrm{CO}_{2}$ discharges into the environment.

Industrial petroleum refining units generate huge amount of heat, which is normally ejected to the environment using either air or cooling water frameworks. Some processes are employed to recover such energy as a part of integration process system as well as for heating in local and commercial operations via hot water network [12].

Energy saving is very significant in process design, and estimating minimum cooling and heating requirement is very important in energy savings issues. Heat integration is a very beneficial tool used in calculating the cost of initial design and waste heat recovery provides environmental benefits for handling unit operators. A wide range of units, such as oil refinery and other industrial processes generate a large amount of heat that is discarded to the environment without reusing in other processes. Such behavior takes into account the recovery of some energy and a part of it is used in process integration. The cooling and heating units are called utility units involving hot utility and cold utility. Hot utility includes furnace, boilers, hot water, steam, and 
generators. Cold utility includes cold water from external source. In recovery system, the process streams exchange heat so as to reduce the cold and hot utility requirements of the heat exchangers, which are the only units in a heat recovery system. Heat exchanger is a unit in which heat is transferred from the hot fluid to the cold fluid. Conventional outline strategies start by planning the reactor, the separation system, the heat exchanger and lastly end by using utilities for providing residual requirements $[2,5,11,13]$.

More recently, we [7] employed the FCC reactor to optimize the process conditions of the operation for the purpose of maximizing the conversion as well as the octane number while minimizing the coke amount in the regenerator based on pilot plant experiments at a very high temperature $\left(460{ }^{\circ} \mathrm{C}-540{ }^{\circ} \mathrm{C}\right)$ requiring high energy consumption in the process. Also, energy consumption for the lab scale is an unimportant issue (ignored) and no extra utility was needed as the quantities of reactants and products were little at laboratory scale, hence recovery issues were not a point in the laboratory-scale operation. However, the design when scaled-up to a commercial level [7] offers the chance of energy savings via appropriate process integration. In commercial operation, heat recovery and energy consumption should be taken into account to decrease environmental effect in addition to reducing the treatment operation cost. Therefore, the main focus of this study is to maximize heat recovery of an industrial fluidized catalytic cracking reactor utilizing the mathematical model developed earlier [7] and then analyze the heat integration process while minimizing overall annual cost of such process.

\section{The experimental data}

The experimental results have been taken from literature [16]. A brief description of the materials, apparatus and experimental procedure used for getting the experimental results are as follows.

The reaction takes place in plug flow reactor $(65 \mathrm{~cm}$ (reactor length) $1.5 \mathrm{~cm}$ (reactor diameter) and $65 \mathrm{~cm}^{3}$ (catalyst bed volume)) with zeolite as a catalyst (pore volume of $0.37\left(\mathrm{~cm}^{3} / \mathrm{g}\right)$ and $338.8\left(\mathrm{~cm}^{2} / \mathrm{g}\right)$ surface area with particle diameter of $75 \mu \mathrm{m}$ having a spherical shape) that should be loaded before each run. The catalyst-to-oil weight ratio (CTO) was adjusted by keeping the catalyst amount loaded and the feedstock (which is vacuum gas oil (VGO)) under the following characterizations: density $\left(\right.$ at $20{ }^{\circ} \mathrm{C}$ ) is 0.919 $\left(\mathrm{g} / \mathrm{cm}^{3}\right)$, Conradson carbon residue (CCR) is 4.13 (wt\%), molecular weight of $400(\mathrm{~g} / \mathrm{mol})$ and sulfur content of $1.61(\mathrm{wt} \%)$ rate constant. Steam was passed over the catalyst bed at a fixed flow rate at a set reaction temperature for 20 min before each run. Liquid products were collected in a glass receiver after condensation and the gaseous products were collected in a gas collecting bottle by water displacement. The spent catalyst was stripped by steam for $30 \mathrm{~min}$ to recover the entrapped hydrocarbons. Subsequently, the catalyst bed was heated to $680{ }^{\circ} \mathrm{C}$ to burn off the coke with oxygen and the intermediate $\mathrm{CO}$ was converted to $\mathrm{CO}_{2}$ by a $\mathrm{CO}$ converter. The total amount of the coke on the spent catalyst was determined by a $\mathrm{CO}_{2}$ infrared detector. The process flow diagram of the experimental setup is shown in Fig. 1. Further information relating to the experimental work can be found in Xiong et al. [16].

\section{Energy consumption and heat recovery of the FCC unit}

In the pilot plant-scale process, heat recovery was not an issue and the energy consumption was negligible, while in industrial processes, energy consumption will be a big issue and heat recovery must be taken into account. A heat integrated system was considered for reducing overall energy consumption (hence reducing environmental effect). However, it is important to incorporate for heat exchangers in the process system. Evaluating the required design is an important issue to minimize the energy consumption and to maximize the energy recovery hence consequently minimizing the capital investment.

Figure 2 describes the heat integration process proposed for FCC unit. Many of utility units operated in series including heaters and coolers and the utility hot units regulate the final temperature of the cold fluid to the required temperature of the reaction, while the utility cold units regulate the final temperature of the hot fluid to a required temperature of the next process.

In general, heat exchanging is working in series with heating and cooling systems. The heater controls the final temperature of the cold liquid to the needed reaction temperature, and the cooler alters the final temperature of the hot liquid to prerequisites of the subsequent stage of the procedure. It is shown in Fig. 2 that the feed stock is pumped by a pump (PU) into a heat exchanger 1 (H.E.1) and heated from $T_{\text {in }}$ to $T_{\text {in } 1}$ it is fed into a heat exchanger 2 (H.E.2) to further heating from $T_{\mathrm{in} 1}$ to $T_{\mathrm{in} 2}$ to the required temperature of the reaction $T_{\mathrm{R}}$ then it is fed to the furnace. The reaction occurs inside a reactor $(R)$, and after completion the hot product stream leaves the reactor and goes to the fractionators (FR). Then it is cooled from $T_{\text {out }}$ to $T_{\text {out } 1}$ via heat exchanger 1 (H.E.1) by contacting with the main feed stock and further cooling via heat exchanger 2 (H.E.2) from $T_{\text {out2 }}$ to $T_{\text {out3 }}$. The final product temperature is cooled from $T_{\text {out }, 1}$ to $T_{\mathrm{F} 1}$ via cooler $(\mathrm{C} 1)$ by contacting with a cold water stream at temperature $T_{\mathrm{W}, 1}$ that is heated into $T_{\mathrm{W}, 2}$. The final product of the other stream temperature is cooled from $T_{\text {out, } 3}$ to 2 


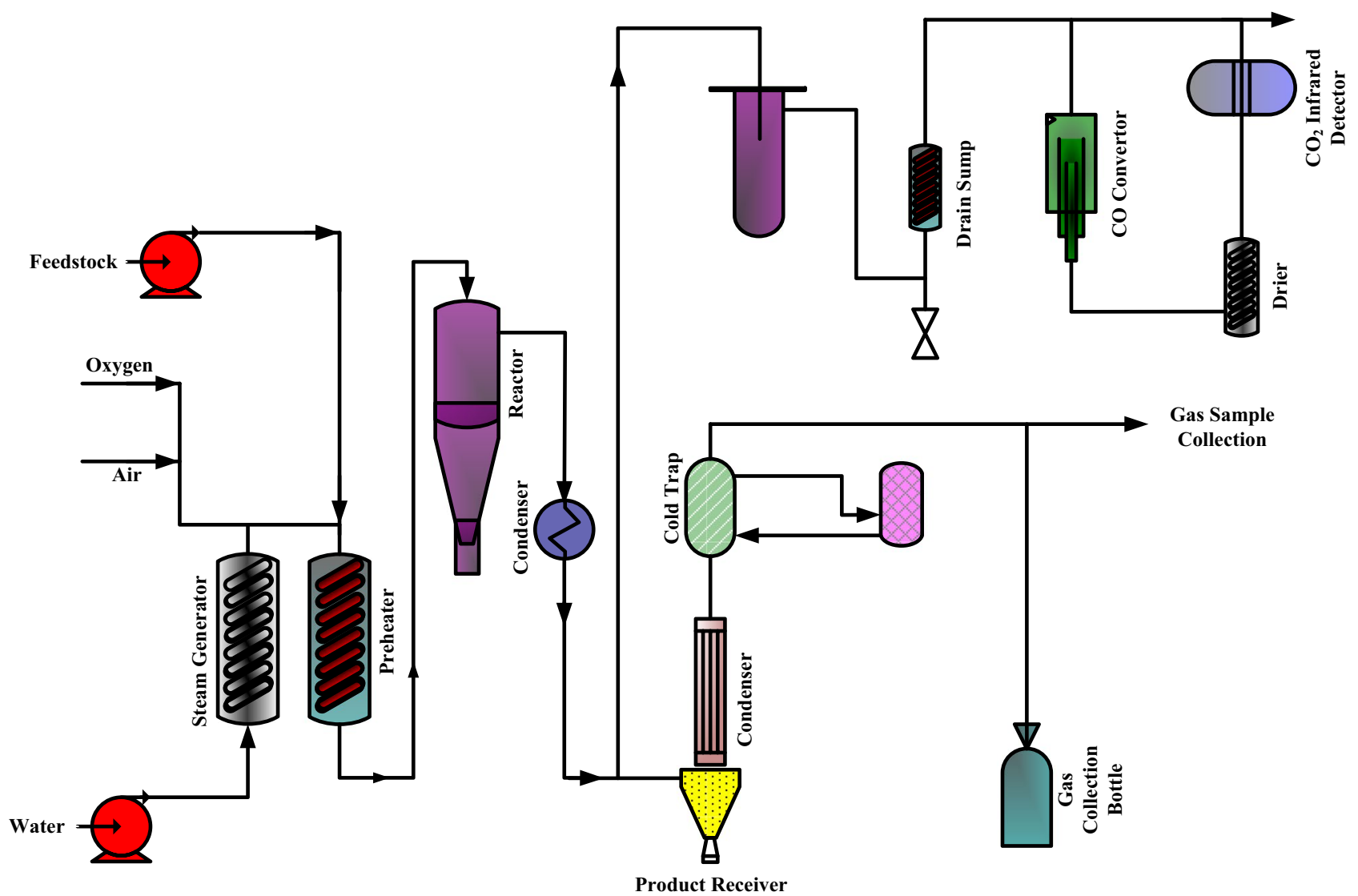

Fig. 1 Process flow diagram of the experimental setup. Adapted from [16]

via cooler (C2) by contacting with the cold water stream at temperature $T_{\mathrm{W}, 3}$, which is heated into $T_{\mathrm{W}, 4}$.

\section{Process model equations}

The main concern of this study is to minimize energy consumption and maximize heat recovery of an industrial fluidized catalytic cracking unit. More recently, we [7] have developed a new mathematical model for the fluidized catalytic cracking operation taking into consideration the complex hydrodynamics of the reactor regenerator system based on a new six-lump kinetic model for the riser. The best kinetic parameters of the relevant reactions have been evaluated employing the optimization technique depending upon the experimental results taken from literature. The optimal operating conditions (mainly, reaction temp $(T)$, catalyst-to-oil ratio (CTO) and weight hourly space velocity (WHSV) on the product composition were investigated and the optimal kinetic parameters obtained from the pilot plant scale were used to develop an industrial fluidized catalytic cracking process. The optimal operating conditions based on maximum conversion of vacuum gas oil with minimum cost in addition to maximizing the octane number of gasoline and coke content deposited on the catalyst within the regenerator, have also been studied. Thus, mass balance equations, energy balance equations, reaction rate equations, catalyst deactivation with the characteristics of the catalyst bed utilized, riser hydrodynamics, regenerator model, dense bed modelling, dilute phase modelling, physical and chemical properties of the reactants and products, equipment and procedure, scale-up of FCC reactor with their optimization processes and results related to the optimal design and operation of such unit can be found with more detail in Jarullah et al. [7]. Therefore, the equations related to the heat exchangers of an industrial FCC reactor utilizing the optimal results obtained previously [7] can be stated as follows:

\section{Heat exchanger 1 (H.E.1)}

The feed stock is pumped through a pump (PU) then it is heated via heat exchanger 1 (H.E1) from $T_{\text {in }}$ to $T_{\text {in } 1}$ with product 1 that leaving the fractionators while product1 is cooled from $T_{\text {out }}$ to $T_{\text {out } 1}$. The heat transfer rate of each stream is shown in Fig. 3 and can be described as follows:

$$
\begin{aligned}
& Q 1_{\mathrm{VGO}}=\left(\rho_{\mathrm{VGO}} c p_{\mathrm{VGO}} Q_{\mathrm{VGO}}\right)\left(T_{\mathrm{in} 1}-T_{\mathrm{in}}\right), \\
& Q 1_{\text {prod. }}=\left(\rho_{\mathrm{LCO}} c p_{\mathrm{LCO}} Q_{\mathrm{LCO}}\right)\left(T_{\mathrm{out}}-T_{\mathrm{out} 1}\right),
\end{aligned}
$$


Fig. 2 Process of heat integration proposed for FCC reactor
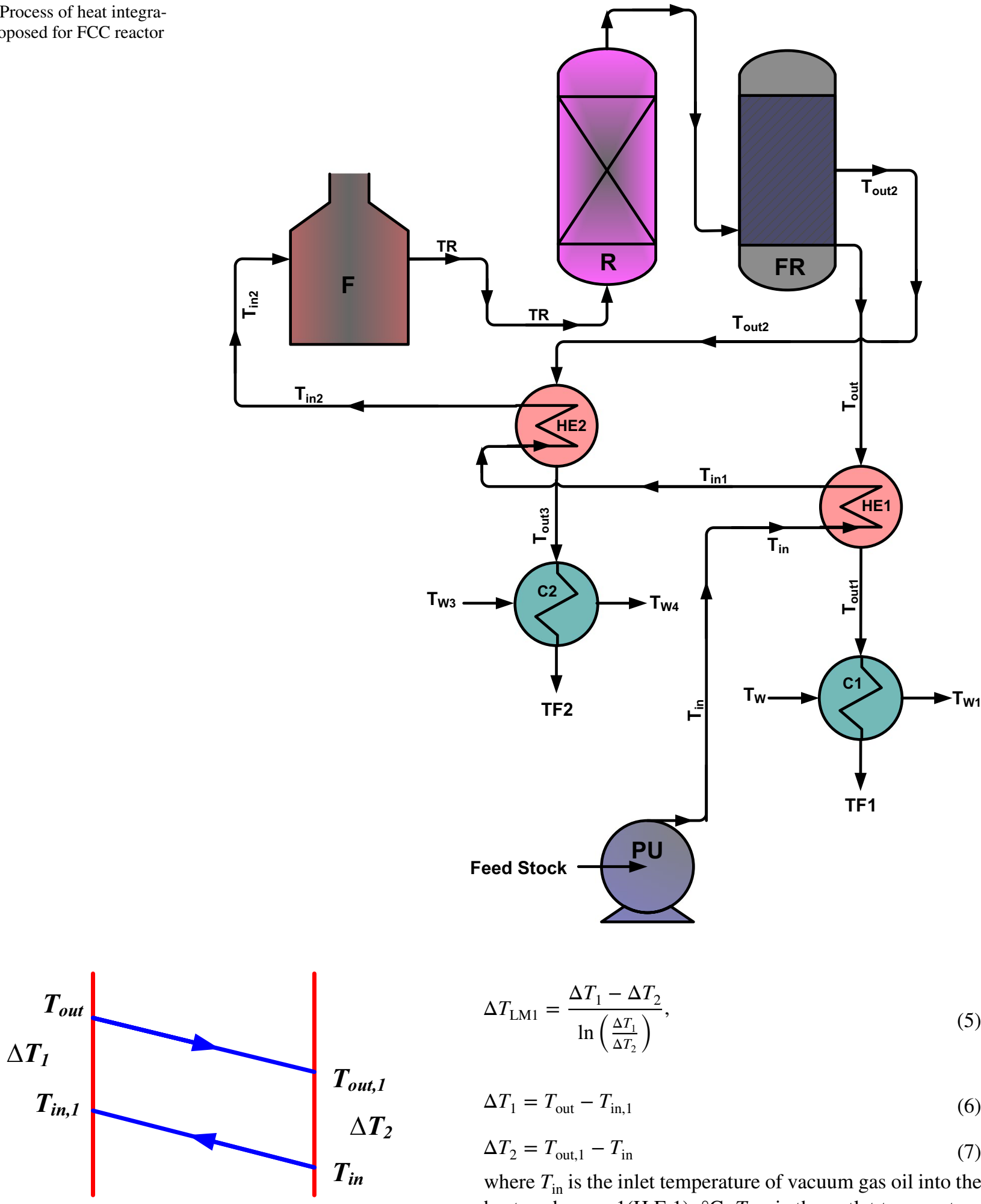

Fig. 3 Temperature gradient of H.E.1

$$
\begin{aligned}
& Q 1_{\mathrm{VGO}}=Q 1_{\text {prod. }}, \\
& Q 1_{\mathrm{VGO}}=U_{1} A_{1} \Delta T_{\mathrm{LM} 1},
\end{aligned}
$$

$\Delta T_{\mathrm{LM} 1}=\frac{\Delta T_{1}-\Delta T_{2}}{\ln \left(\frac{\Delta T_{1}}{\Delta T_{2}}\right)}$,

$\Delta T_{1}=T_{\text {out }}-T_{\text {in, } 1}$

$\Delta T_{2}=T_{\text {out }, 1}-T_{\text {in }}$

where $T_{\mathrm{in}}$ is the inlet temperature of vacuum gas oil into the heat exchanger 1 (H.E.1), ${ }^{\circ} \mathrm{C} ; T_{\mathrm{in}, 1}$ is the outlet temperature of phenol from heat exchanger 1 (H.E.1), ${ }^{\circ} \mathrm{C} ; T_{\text {out }}$ is the inlet temperature of hot product mixture into the heat exchanger 1(H.E.1), ${ }^{\circ} \mathrm{C} ; T_{\text {out }, 1}$ is the outlet temperature of hot product mixture from heat exchanger 1 (H.E.1), ${ }^{\circ} \mathrm{C} ; Q_{\mathrm{VGO}}$ is the volumetric flow rate of feed stock, $\mathrm{cm}^{3} / \mathrm{s} ; Q_{\mathrm{LCO}}$ is the volumetric flow rate of light cycle oil, $\mathrm{cm}^{3} / \mathrm{s} ; A_{1}$ is the heat transfer area 
of heat exchanger 1(H.E.1); $\rho_{\mathrm{VGO}}$ is the density of VGO, $\mathrm{g} / \mathrm{cm}^{3} ; \mathrm{cp}_{\mathrm{VGO}}$ is the specific heat capacity of $\mathrm{VGO}, \mathrm{J} / \mathrm{g} \mathrm{K}$; $\rho_{\mathrm{LCO}}$ is the density of $\mathrm{LCO}, \mathrm{g} / \mathrm{cm}^{3} ; \mathrm{cp}_{\mathrm{LCO}}$ is the specific heat capacity of $\mathrm{LCO}, \mathrm{J} / \mathrm{g} \mathrm{K} ; U_{1}$ is the overall heat transfer coefficient for heat exchanger 1 (H.E.1), $\mathrm{W} / \mathrm{m}^{2} \mathrm{~K} ; \Delta T_{\mathrm{LM} 1}$ is the $\log$ mean temperature difference for heat exchanger 1(H.E.1); $Q 1_{\mathrm{VGO}}$ is the heat duty of feed stock in heat exchanger 1(H.E.1), W; and $Q 1_{\text {prod. }}$ is the heat duty of product mixture in heat exchanger 1(H.E.1), W.

\section{Heat exchanger 2 (H.E.2)}

The feed stock stream leaving the H.E.1 is passed through H.E. 2 for raising the feed temperature. The stream of product mixture 2 out of FR is used to heat the feed into heat exchanger 2 (H.E.2). In this case, the feed is heated from $T_{\mathrm{in} 1}$ to $T_{\text {in2 }}$ and at the same time the product mixture 2 is cooled from $T_{\text {out } 2}$ to $T_{\text {out } 3}$ as shown in Fig. 4 . The equations used in heat exchanger 2 (H.E.2) are:

$$
\begin{aligned}
& Q 2_{\mathrm{VGO}}=\left(\rho_{\mathrm{VGO}} c p_{\mathrm{VGO}} Q_{\mathrm{VGO}}\right)\left(T_{\mathrm{in} 2}-T_{\mathrm{in} 1}\right), \\
& Q 2_{\mathrm{prod} .}=\left(\rho_{\mathrm{GLN}} c p_{\mathrm{GLN}} Q_{\mathrm{GLN}}\right)\left(T_{\mathrm{out}, 2}-T_{\mathrm{out}, 3}\right), \\
& Q 2_{\mathrm{VGO}}=U_{2} A_{2} \Delta T_{\mathrm{LM} 2}, \\
& Q 2_{\mathrm{VGO}}=Q 2_{\text {prod. }}
\end{aligned}
$$

$\Delta T_{\mathrm{LM} 2}=\frac{\Delta T_{3}-\Delta T_{4}}{\ln \left(\frac{\Delta T_{3}}{\Delta T_{4}}\right)}$,

$\Delta T_{3}=T_{\text {out }, 2}-T_{\text {in } 2}$,

$\Delta T_{4}=T_{\text {out }, 3}-T_{\text {in } 1}$,

where $T_{\text {in } 2}$ is the feed stock outlet temperature into heat exchanger 2 (H.E.2), ${ }^{\circ} \mathrm{C} ; T_{\text {out } 3}$ is the outlet temperature of product mixture 2 from heat exchanger 2 (H.E.2), ${ }^{\circ} \mathrm{C}$; $T_{\text {out }, 2}$ is the inlet temperature of product mixture 2 from heat exchanger 2 (H.E.2), ${ }^{\circ} \mathrm{C} ; A_{2}$ is the heat transfer area of heat exchanger 2 (H.E.2), $\mathrm{m}^{2} ; \rho_{\mathrm{GLN}}$ is the density of gasoline
(GLN), $\mathrm{g} / \mathrm{cm}^{3} ; \mathrm{cp}_{\mathrm{GLN}}$ is the specific heat capacity of GLN, $\mathrm{J} / \mathrm{g} \mathrm{K} ; U_{2}$ is the overall heat transfer coefficient for heat exchanger 2 (H.E.2), $\mathrm{W} / \mathrm{m}^{2} \mathrm{~K} ; \Delta T_{\mathrm{LM}, 2}$ is the log mean temperature difference for heat exchanger 2 (H.E.2), $\mathrm{K} ; Q 2$ prod. is the heat duty of product mixture 2 in heat exchanger 2 (H.E.2), W; and $Q_{\mathrm{GLN}}$ is the volumetric flow rate of gasoline, $\mathrm{cm}^{3} / \mathrm{s}$.

\section{Cooler 1 (C1)}

The outlet stream product mixture from heat exchanger 1 (H.E.1) will be cooled through a cooler (C1) from $T_{\text {out }, 1}$ to $T_{\mathrm{F} 1}$ using water as a cold fluid at temperature $T_{\mathrm{W}, 1}$ heated to $T_{\mathrm{W}, 2}$, described in Fig. 5. The equations used in cooler 1 are:

$Q 3_{w}=m_{\mathrm{W}} \mathrm{cp}^{\mathrm{W}}\left(T_{\mathrm{W}, 2}-T_{\mathrm{W}, 1}\right)$,

$Q 3_{\text {prod. }}=\left(\rho_{\mathrm{LCO}} \mathrm{cp}_{\mathrm{LCO}} Q_{\mathrm{LCO}}\right)\left(T_{\mathrm{out}, 1}-T_{\mathrm{F} 1}\right)$,

$Q 3_{w}=Q 3_{\text {prod. }}$,

$Q 3_{\mathrm{w}}=U_{3} A_{3} \Delta T_{\mathrm{LM}, 3}$,

$\Delta T_{\mathrm{LM}, 3}=\frac{\Delta T_{5}-\Delta T_{6}}{\ln \left(\frac{\Delta T_{5}}{\Delta T_{6}}\right)}$,

$\Delta T_{5}=T_{\text {out }, 1}-T_{\mathrm{W}, 2}$,

$\Delta T_{6}=T_{\mathrm{F}}-T_{\mathrm{W}, 1}$,

where $T_{\mathrm{F} 1}$ is the outlet final temperature of product mixture from cooler, ${ }^{\circ} \mathrm{C} ; T_{\mathrm{W}, 1}$ is the inlet temperature of water into cooler, ${ }^{\circ} \mathrm{C} ; T_{\mathrm{W}, 2}$ is the outlet temperature of water from cooler, ${ }^{\circ} \mathrm{C} ; m_{\mathrm{W}}$ is the mass flow rate of cooling water, $\mathrm{g} / \mathrm{s}$; $\mathrm{cp}^{\mathrm{W}}$ is the specific heat capacity of water, $\mathrm{J} / \mathrm{g} \mathrm{K} ; A_{3}$ is the heat transfer area of cooler, $\mathrm{m}^{2} ; U_{3}$ is the overall heat transfer coefficient for cooler, $\mathrm{W} / \mathrm{m}^{2} \mathrm{~K} ; \Delta T_{\mathrm{LM}, 3}$ is the log mean temperature difference for cooler, $(\mathrm{K}) ; Q 3_{w}$ is the heat duty of water in cooler, $\mathrm{W}$; and $Q 3_{\text {prod. }}$. the heat duty of product mixture in cooler, $\mathrm{W}$.

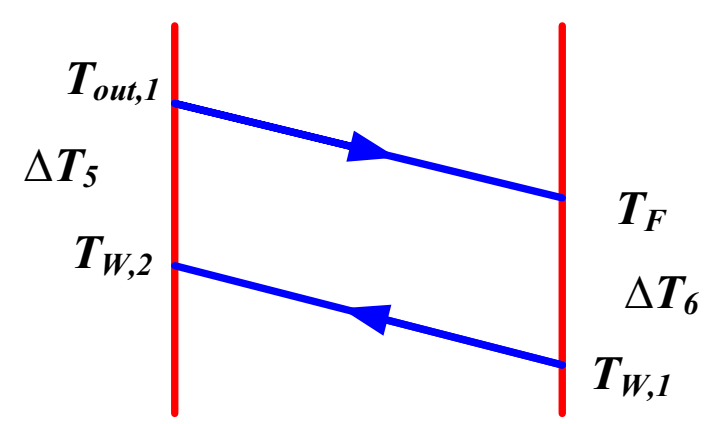

Fig. 5 Temperature gradient of cooler 1 (C1)
Fig. 4 Temperature gradient of H.E.2

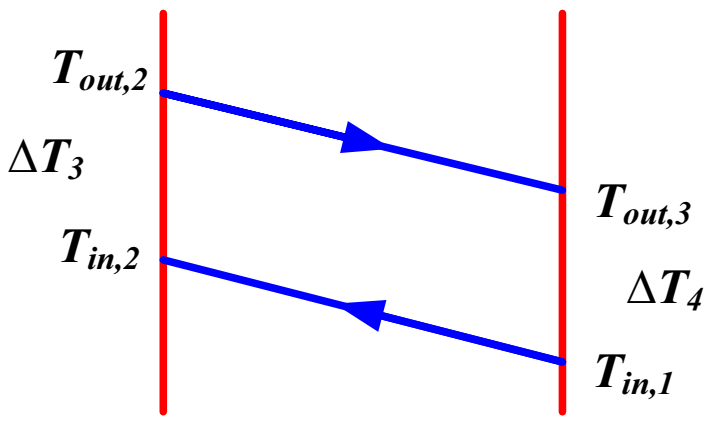

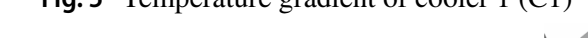




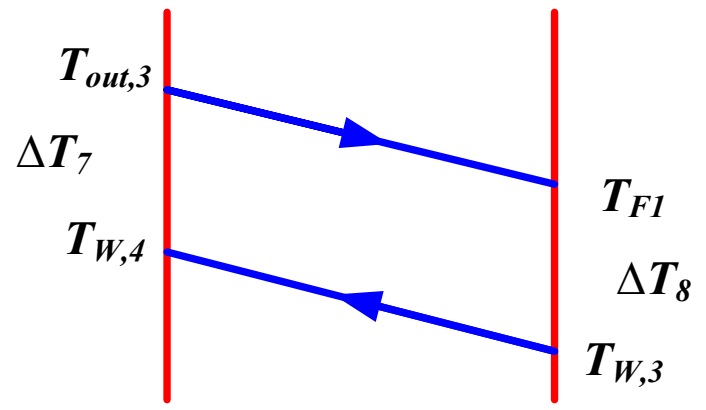

Fig. 6 Temperature gradient of cooler (C2)

\section{Cooler 2 (C2)}

The outlet stream product mixture 2 from heat exchanger 2 (H.E.2) will be cooled through a cooler (C2) from $T_{\text {out }, 3}$ to $T_{\mathrm{F} 2}$ using water as a cold fluid at temperature $T_{\mathrm{W}, 2}$ heated to $T_{\mathrm{W}, 4}$, described in Fig. 6 . The equations used in cooler 2 are:

$Q 4_{w}=m_{\mathrm{W} 2} \mathrm{cp}^{\mathrm{W}}\left(T_{\mathrm{W}, 2}-T_{\mathrm{W}, 1}\right)$,

$Q_{\text {prod. }}=\left(\rho_{\mathrm{LCO}} \mathrm{cp}_{\mathrm{LCO}} Q_{\mathrm{LCO}}\right)\left(T_{\mathrm{out}, 1}-T_{\mathrm{F}}\right)$

$Q 4_{w}=Q 4_{\text {prod. }}$,

$Q 4_{w}=U_{4} A_{4} \Delta T_{\mathrm{LM}, 3}$,

$\Delta T_{\mathrm{LM}, 4}=\frac{\Delta T_{8}-\Delta T_{7}}{\ln \left(\frac{\Delta T_{8}}{\Delta T_{7}}\right)}$,

$\Delta T_{7}=T_{\text {out }, 3}-T_{\mathrm{W}, 4}$,

$\Delta T_{8}=T_{\mathrm{F} 1}-T_{\mathrm{W}, 3}$,

where $T_{\mathrm{F} 1}$ is the outlet final temperature of product mixture 1 from cooler $2,{ }^{\circ} \mathrm{C} ; T_{\mathrm{W}, 3}$ is the inlet temperature of water into cooler $2,{ }^{\circ} \mathrm{C} ; T_{\mathrm{W}, 4}$ is the outlet temperature of water from cooler $2,{ }^{\circ} \mathrm{C} ; m_{\mathrm{W} 2}$ is the mass flow rate of cooling water, $\mathrm{gm} / \mathrm{s} ; \mathrm{cp}^{\mathrm{W}}$ is the specific heat capacity of water, $\mathrm{J} / \mathrm{g} \mathrm{K} ; A_{4}$ is the heat transfer area of cooler $2, \mathrm{~m}^{2} ; U_{4}$ is the overall heat transfer coefficient for cooler $2, \mathrm{~W} / \mathrm{m}^{2} \mathrm{~K} ; \Delta T_{\mathrm{LM}, 4}$ is the $\log$ mean temperature difference for cooler $2,(\mathrm{~K}) ; Q 4_{\mathrm{w}}$ is the heat duty of water in cooler $2, \mathrm{~W} ; Q^{4}$ prod is the heat duty of product mixture in cooler $2, \mathrm{~W}$.

The total heat transfer area $\left(A_{t}, \mathrm{~m}^{2}\right)$ can be calculated as follows:

$A_{t}=A_{1}+A_{2}+A_{3}+A_{4}$.

\section{Furnace 1 (F1)}

Furnace is needed to further raise the feed temperature to obtain the reaction temperature $T_{\mathrm{R}}$. In this case, the feed stock is fed into furnace $(F 1)$ separately to preheat the feed from $T_{\text {in2 }}$ to the required temperature of the reaction $T_{\mathrm{R}}$. The equations of furnace used are:

$\mathrm{QF}=\left(\rho_{\mathrm{VGO}} \mathrm{cp}_{\mathrm{VGO}} Q_{\mathrm{VGO}}\right)\left(T_{\mathrm{R}}-T_{\mathrm{in} 2}\right)$

where $Q_{\mathrm{VGO}}$ is the heat duty of VGO in furnace, W; and $Q F$ is the total heat duty in furnace, $\mathrm{W}$.

It is known that the physical properties such as density, heat capacity, etc., are temperature dependent that can be calculated (in each equipment) using the following equation:

$T_{\text {av }}=\frac{T_{\text {in }}+T_{\text {out }}}{2}$

where $T_{\text {in. }}$ and $T_{\text {out }}$ are inlet and outlet temperatures for item of each equipment, respectively.

\section{Optimization problem formulation}

The optimization process as a function of the cost models of the whole process is presented here. The overall annual process cost can be calculated using the following relationship [14]:

$\mathrm{OAPC}=\mathrm{ACC}+\mathrm{OPC}$,

where OPAC is the overall annual process cost (\$/year).

The annualized capital cost (ACC, \$/year) can be calculated from the total capital cost (TCC, \$), which includes the cost of the main equipment in the unit process such as reactor, compressor, heat exchanger, pump and furnace:

Annualized capital cost $(\mathrm{ACC}, \$ / \mathrm{yr})=$ Total capital cost $(T C C, \$)$

$$
\times \frac{i(1+i)^{N}}{(1+i)^{N-1}}
$$

$N$ is number of years and $i$ is the fractional interest per year; $N=10$ years, $i=5 \%$ [14].

The total capital cost (TCC, \$) can be calculated from the following equation [15]:

Total capital cost (TCC, \$)

$=$ Capital cost of installed equipment $(\mathrm{CC}, \$)$

$\times 1.4$,

Capital cost of installed equipment $(\mathrm{CC}, \$)$

$=$ reactor $\operatorname{cost}\left(C_{\mathrm{r}}\right)+$ heat exchanger

$\operatorname{Cost}\left(C_{\text {heatexch. }}\right)+\operatorname{pump} \operatorname{cost}\left(C_{\text {Pump }}\right)$

+ Furnace cost $\left(C_{\text {Furn. }}\right)$,

The operating cost (OPC) in Eq. (32) above is determined utilizing the following equation [15]:

$\mathrm{OPC}(\$ /$ year $)=$ Variable operating cost $($ VOPC $)$ 
Variable operating cost(VOPC, $\$ / \mathrm{yr})$

$$
\begin{aligned}
= & \text { Heating } \operatorname{cost}\left(C_{\text {Heating }}\right)+\text { pumping } \operatorname{cost}\left(C_{\text {Pumping }}\right) \\
& + \text { cooling } \operatorname{cost}\left(C_{\text {cooling }}\right)
\end{aligned}
$$

- Heating cost $\left(C_{\text {Heating }}\right)(\$ / y r)$ :

$$
\begin{aligned}
& C_{\text {Heating }}(\$ / \text { year }) \\
& =\left(Q_{F}(\mathrm{~kW})\right)\left(\frac{0.06 \$}{\mathrm{kWh}}\right)\left(\frac{24 \mathrm{~h}}{1 \text { day }}\right)\left(\frac{342 \text { days }}{1 \text { year }}\right)
\end{aligned}
$$

- Pumping cost $\left(C_{\text {Pumping }}\right)(\$ / y r)$ :

$$
\begin{aligned}
& C_{\text {pumping }}(\$ / \text { year }) \\
& =\left(Q_{p}(\mathrm{~kW})\right)\left(\frac{0.06 \$}{\mathrm{kWh}}\right)\left(\frac{24 \mathrm{~h}}{1 \text { day }}\right)\left(\frac{342 \text { days }}{\text { year }}\right)
\end{aligned}
$$

- Cooling cost $\left(C_{\text {cooling }}\right)(\$ /$ year $)$ can be estimated by the following relationship with a price of cooling water $(0.00375 \$ / \mathrm{kg})$ [8]:

$$
\begin{aligned}
& C_{\text {cooling }}(\$ / \text { year }) \\
& =\left(m_{\mathrm{W}}\left(\frac{\mathrm{kg}}{\mathrm{h}}\right)\right)\left(\frac{0.00375 \$}{\mathrm{~kg}}\right)\left(\frac{24 \mathrm{~h}}{1 \text { day }}\right)\left(\frac{342 \text { days }}{\text { year }}\right) .
\end{aligned}
$$

Others capital cost (CC, \$) for each term can be calculated as follows $[5,15]$ :

- Reactor cost $\left(C_{\mathrm{r}}\right)(\$)$ :

$$
C_{\mathrm{r}}(\$)=\left(\frac{M \& S}{280}\right) 101.9 D_{\mathrm{r}}^{1.066} L_{\mathrm{r}}^{0.802}\left(2.18+F_{c}\right)
$$

$F_{c}=F_{m} F_{p}$

$D_{\mathrm{r}}$ and $L_{\mathrm{r}}$ are the reactor diameter and length, respectively. $M \& S$ is Marshal and Swift index for cost escalation (M \& $S=1536.5)$ [3].

$F_{c}, F_{m}$ and $F_{p}$ are dimensionless factors that are function of the construction material and operating pressure $\left(F_{m}=3.67, F_{p}=3.93\right)[5,4]$.

- Heat exchanger cost $\left(C_{\text {heatexch. }}\right)(\$)$ :

$$
\begin{aligned}
& C_{\text {heatexch. }}(\$)=\left(\frac{M \& S}{280}\right) 210.78 A_{t}^{0.65}\left(2.29+F_{c}\right), \\
& F_{c}=F_{m}\left(F_{d}+F_{p}\right) .
\end{aligned}
$$

- Pump cost $\left(C_{\text {Pump }}\right)(\$)$ :

$$
C_{\text {Pump }}(\$)=\left(\frac{M \& S}{280}\right) 9.84 \times 10^{3} F_{c}\left(\frac{Q_{p}}{4}\right)^{0.55},
$$

$$
F_{c}=F_{m} F_{p} F_{T} .
$$

- Furnace cost $\left(C_{\text {Furn }}\right)(\$)$ :

$C_{\text {Furn. }}(\$)=\left(\frac{M \& S}{280}\right) 5.52 \times 103 Q_{F}^{0.85}\left(1.27+F_{c}\right)$,

$F_{c}=F_{m}+F_{p}+F_{d}$,

where $\mathrm{QF}$ is the heat duty of the furnace, $\mathrm{W} ; F_{m}, F_{p}$, $F_{c}, F_{d}$ and $F_{T}$ are dimensionless factors that are functions of the construction material, operating pressure and temperature in addition to the design type.

The optimization problem can be stated as shown below:

Given

Inlet temperature of feed stock $T_{\mathrm{in}, 0}$, outlet product mixture $1 T_{\text {out } 1}$, outlet product mixture $2 T_{\text {out } 2}$ reaction temperature $T_{\mathrm{R}}$, inlet water temperature $T_{\mathrm{W}, 1}, T_{\mathrm{W}, 3}$ volumetric flow rates of feed stock $\left(Q_{\mathrm{VGO}}\right)$

Optimize $\quad T_{\mathrm{F}}, T_{\mathrm{W}, 2}$

So as to minimize The total annual cost of the process (OAPC)

Subjected to Process constraints and linear bounds on all decision variables

The optimization problem can mathematically be represented as follows:

Min OAPC

$T_{\mathrm{F}}, T_{\mathrm{W}, 2}$

s.t. $f(x(z), u(z), v)$ (model, equality constraints)

$T_{\mathrm{F}}^{L}<T_{\mathrm{F}}<T_{\mathrm{F}}^{U}$ (inequality constraints)

$T_{\mathrm{W}, 2}^{\mathrm{L}}<T_{\mathrm{W}, 2}<T_{\mathrm{W}, 2}^{U}$ (inequality constraints)

$\Delta T_{\mathrm{W}, 2}^{L}<\Delta T_{\mathrm{W}, 2}<\Delta T_{\mathrm{W}, 2}^{U}$ (inequality constraints)

$\Delta T_{\mathrm{F}}^{L}<\Delta T_{\mathrm{F}}<\Delta T_{\mathrm{F}}^{U}$ (inequality constraints)

$T_{\mathrm{F}}=T_{\mathrm{F}} *$ (equality constraints),

where $\Delta T_{\mathrm{W}, 2}$ is the temperature difference between inlet and outlet temperature of water in the cooler. Practically, the best temperature difference between inlet and outlet water in the cooler is $5-25^{\circ} \mathrm{C} . \Delta T_{\mathrm{F}}$ is the temperature difference between inlet and outlet temperature of feed stock in the furnace. $T_{\mathrm{F}}{ }^{*}$ is the target final temperature of the product. The optimization solution method used by gPROMS is a two-step method known as feasible path approach. The first step performs the simulation to converge all the equality constraints (described by f) and to satisfy the inequality constraints. The second step performs the optimization (updates the values of the decision variables such as the kinetic parameters) [10]. The optimization problem is posed as a nonlinear programming (NLP) problem and is solved using a successive quadratic programming (SQP) method within gPROMS software. 


\section{Results and discussion}

\section{Kinetic parameters estimation}

The optimal set of kinetic parameters of an industrial fluidized catalytic cracking reactions was estimated utilizing the objective function via minimizing the sum of squared error between the experimental results and the model results including all the data related to the product compositions, which are presented in Jarullah et al. [7]. The kinetic parameters have been calculated employing nonlinear approach, where such regression is used to calculate the order of the reactions [VGO reactions order $\left(n_{1}\right)$, LCO reactions order $\left(n_{2}\right)$, GLN reactions order $\left(n_{3}\right)$, LPG reactions order $\left(n_{4}\right)$ ], activation energies and pre-exponential factors for all reactions related to the FCC reactions, simultaneously. These kinetic parameters were obtained accurately among all results based on average absolute error of less than $5 \%$, and hence can be confidently utilized for reactor design, operation and control. The optimal kinetic parameters with the optimal operating conditions results are summarized in Table 1 for convenience (more details related to the kinetic parameters, maximum conversion and octane number, minimum coke content, etc., can be found in Jarullah et al. [7].

Figure 7 shows the parity plots of the experimental and predicted yields of LCO, GLN, DG and coke in an industrial fluidized catalytic cracking unit. All the plots reveal straight lines with slops close to unity. Hence, excellent

Table 1 Optimal kinetic parameters and operating conditions obtained for industrial FCC process

\begin{tabular}{|c|c|c|c|}
\hline Parameter & Symbol & Unit & Value \\
\hline Order of vacuum gas oil concentration & $n_{1}$ & $(-)$ & 0.925367 \\
\hline Order of light cycle oil concentration & $n_{2}$ & $(-)$ & 1.000001 \\
\hline Order of gasoline concentration & $n_{3}$ & $(-)$ & 0.999785 \\
\hline Order of liquefied petroleum gases concentration & $n_{4}$ & $(-)$ & 0.999413 \\
\hline Activation energy for reaction $\mathrm{VGO} \rightarrow \mathrm{LCO}$ & $E_{1}$ & $\mathrm{~kJ} / \mathrm{mol}$ & 20431.1 \\
\hline Activation energy for reaction $\mathrm{VGO} \rightarrow \mathrm{GLN}$ & $E_{2}$ & $\mathrm{~kJ} / \mathrm{mol}$ & 23082.6 \\
\hline Activation energy for reaction $\mathrm{VGO} \rightarrow \mathrm{LPG}$ & $E_{3}$ & $\mathrm{~kJ} / \mathrm{mol}$ & 23082.6 \\
\hline Activation energy for reaction $\mathrm{VGO} \rightarrow \mathrm{DG}$ & $E_{4}$ & $\mathrm{~kJ} / \mathrm{mol}$ & 22271.8 \\
\hline Activation energy for reaction $\mathrm{VGO} \rightarrow \mathrm{CK}$ & $E_{5}$ & $\mathrm{~kJ} / \mathrm{mol}$ & 9006.57 \\
\hline Activation energy for reaction $\mathrm{LCO} \rightarrow \mathrm{GLN}$ & $E_{6}$ & $\mathrm{~kJ} / \mathrm{mol}$ & 49215.6 \\
\hline Activation energy for reaction $\mathrm{LCO} \rightarrow \mathrm{CK}$ & $E_{7}$ & $\mathrm{~kJ} / \mathrm{mol}$ & 19854.4 \\
\hline Activation energy for reaction GLN $\rightarrow$ LPG & $E_{8}$ & $\mathrm{~kJ} / \mathrm{mol}$ & 70463.8 \\
\hline Activation energy for reaction GLN $\rightarrow$ DG & $E_{9}$ & $\mathrm{~kJ} / \mathrm{mol}$ & 88051.1 \\
\hline Activation energy for reaction $\mathrm{LPG} \rightarrow \mathrm{DG}$ & $E_{10}$ & $\mathrm{~kJ} / \mathrm{mol}$ & 65992.4 \\
\hline Pre-exponential factor for reaction $\mathrm{VGO} \rightarrow \mathrm{LCO}$ & $A_{1}$ & $\left(\mathrm{~cm}^{3} / \mathrm{g}\right) 0.074633 \mathrm{~s}^{-1}$ & $8.15295 \times 106$ \\
\hline Pre-exponential factor for reaction $\mathrm{VGO} \rightarrow \mathrm{GLN}$ & $A_{2}$ & $\left(\mathrm{~cm}^{3} / \mathrm{g}\right) 0.074633 \mathrm{~s}^{-1}$ & 391.828 \\
\hline Pre-exponential factor for reaction VGO $\rightarrow$ LPG & $A_{3}$ & $\left(\mathrm{~cm}^{3} / \mathrm{g}\right) 0.074633 \mathrm{~s}^{-1}$ & 1276.72 \\
\hline Pre-exponential factor for reaction $\mathrm{VGO} \rightarrow \mathrm{DG}$ & $A_{4}$ & $\left(\mathrm{~cm}^{3} / \mathrm{g}\right) 0.074633 \mathrm{~s}^{-1}$ & 1656.55 \\
\hline Pre-exponential factor for reaction $\mathrm{VGO} \rightarrow \mathrm{Ck}$ & A5 & $\left(\mathrm{cm}^{3} / \mathrm{g}\right) 0.074633 \mathrm{~s}^{-1}$ & 1204.11 \\
\hline Pre-exponential factor for reaction $\mathrm{LCO} \rightarrow \mathrm{GLN}$ & $A_{6}$ & $\mathrm{~s}^{-1}$ & 598.233 \\
\hline Pre-exponential factor for reaction $\mathrm{LCO} \rightarrow \mathrm{CK}$ & $A_{7}$ & $\mathrm{~s}^{-1}$ & 20986.8 \\
\hline Pre-exponential factor for reaction $\mathrm{GLN} \rightarrow \mathrm{LPG}$ & $A_{8}$ & $\left(\mathrm{~cm}^{3} \mathrm{~g}\right) 0.000215 \mathrm{~s}^{-1}$ & $3.0214 \times 107$ \\
\hline Pre-exponential factor for reaction $\mathrm{VGO} \rightarrow \mathrm{DG}$ & $A_{9}$ & $\left(\mathrm{~cm}^{3} \mathrm{~g}\right) 0.000215 \mathrm{~s}^{-1}$ & $1.46191 \times 107$ \\
\hline Pre-exponential factor for reaction $\mathrm{LPG} \rightarrow \mathrm{DG}$ & $A_{10}$ & $\left(\mathrm{~cm}^{3} \mathrm{~g}\right) 0.000215 \mathrm{~s}^{-1}$ & 28090.8 \\
\hline Sum of Square Errors & SSE & $(-)$ & $4.42621 \times 10^{-7}$ \\
\hline Operating conditions & Symbol & Unit & Values \\
\hline \multicolumn{4}{|c|}{ Optimal operating conditions obtained for industrial FCC process } \\
\hline Reaction temperature & TR & $\mathrm{K}$ & 820.012 \\
\hline Weight Hourly space velocity & WHSV & $\mathrm{hr}^{-1}$ & 2.002 \\
\hline Catalyst-to-oil ratio & CTO & $(-)$ & 10.00 \\
\hline Conversion & $\mathrm{CV}$ & $(-)$ & 87.6075 \\
\hline Octane number & Octane number & $(-)$ & 97.5722 \\
\hline
\end{tabular}



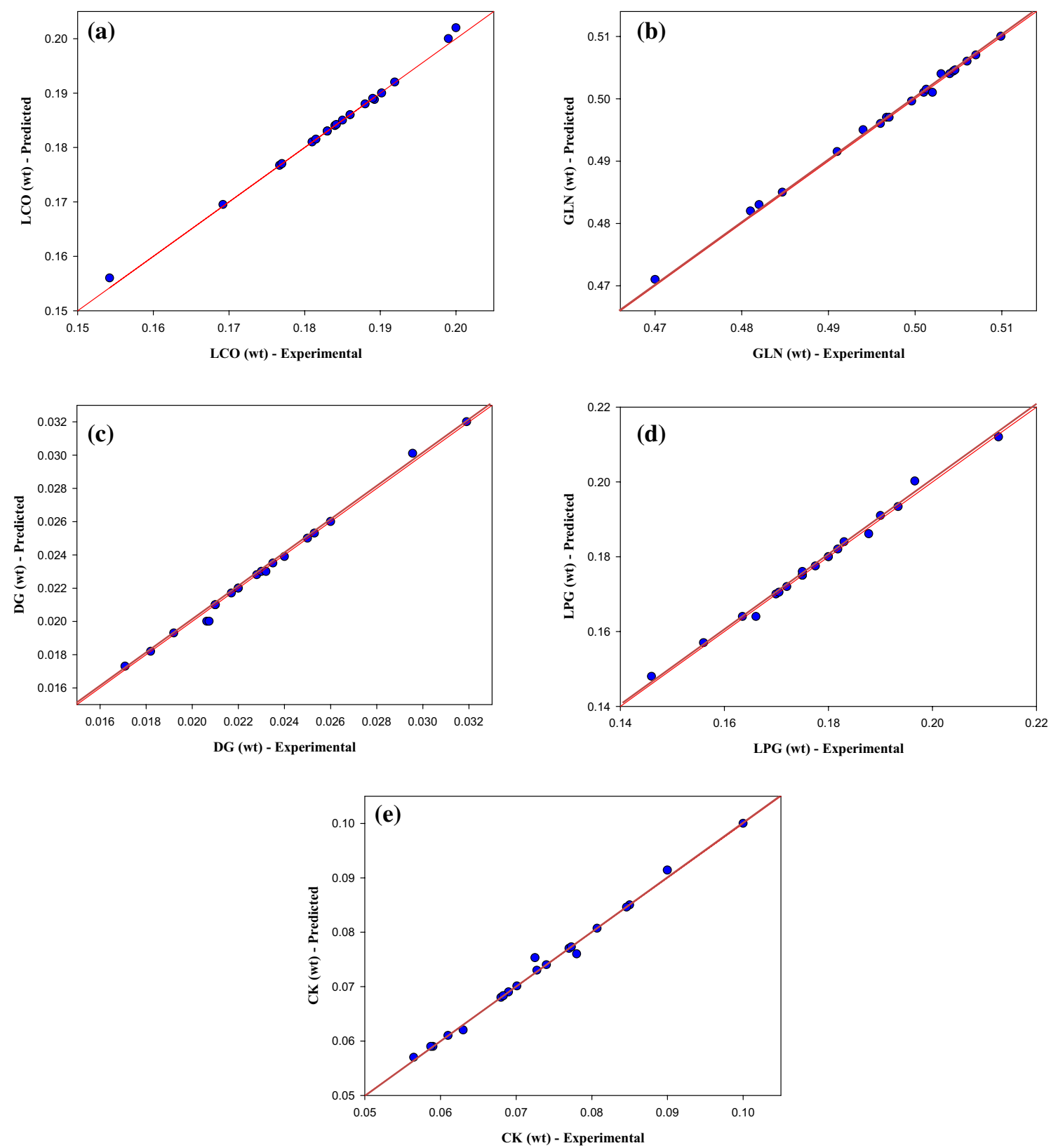

Fig. 7 Comparison between the experimental and simulated data for a light cycle oil, $\mathbf{b}$ gasoline, $\mathbf{c}$ dry gaseous, $\mathbf{d}$ liquefied petroleum gases, $\mathbf{e}$ coke

agreement was achieved between the pilot plant data of the unit and the simulated results of this study. Thus, the model can be employed for describing the performance of the industrial fluidized catalytic cracking reactions at several operating conditions for which experimental data are not available.

\section{Energy recovery and cost savings}

Here, an industrial fluidized catalytic cracking operation with energy consumption and heat recovery choice is regarded to reduce overall energy consumption (subsequently lessening environmental impact). Notwithstanding, various heat exchangers are added to the process. The goal is to provide a retrofit outline for the purpose of reducing the energy consumption and maximizing the heat recovery leading to reduce the capital investment. The heater controls the final temperature of the cold liquid to the required reaction temperature, and the cooler sets out the final temperature of the hot liquid to necessities of the following stage of the operation. 
Table 2 Values of parameters employed in this model

\begin{tabular}{llr}
\hline Parameter & Unit & Value \\
\hline$T_{\text {in, } 0}$ & ${ }^{\circ} \mathrm{C}$ & 24 \\
$T_{\text {out }}$ & ${ }^{\circ} \mathrm{C}$ & 347 \\
$T_{\text {out } 2}$ & ${ }^{\circ} \mathrm{C}$ & 192 \\
$T_{\mathrm{W}, 1}$ & ${ }^{\circ} \mathrm{C}$ & 20 \\
$U_{1}$ & $\mathrm{~W} / \mathrm{m}^{2} \mathrm{~K}$ & 150 \\
$U_{2}$ & $\mathrm{~W} / \mathrm{m}^{2} \mathrm{~K}$ & 900 \\
\hline
\end{tabular}

Table 3 Dimensionless constants used in this model

\begin{tabular}{llll}
\hline $\begin{array}{l}\text { Dimensionless } \\
\text { parameters }\end{array}$ & Furnace & Pump & Heat exchanger \\
\hline$F_{m}$ & 0.75 & 1 & 3.75 \\
$F_{p}$ & 0.15 & 1.9 & 0.625 \\
$F_{d}$ & 1 & 0 & 1 \\
$F_{T}$ & 0 & 1 & 0 \\
\hline
\end{tabular}

In this study, the values of the constant parameters with factors, coefficients and dimensionless constants are listed in Tables 2 and 3. Process heat integration variables are evaluated and optimized which are summarized in Table 4.

Based on the results presented in Table 4, it is observed that the minimum total cost $\left(C_{\mathrm{t}}\right)$ and amounts of cooling water $\left(m_{\mathrm{w}}\right)$ with heating integration of the fluidized catalytic cracking process are less than those obtained without heating integration. Also, it is noticed that the cost saving is $(34.87 \%)$ in comparison with the cost obtained without heating integration to reach reaction temperature and to minimize the final product temperature. To achieve the target final temperature of the product $\left(26^{\circ} \mathrm{C}\right)$, it is noticed that the amount of cooling water needed to reach the final temperature without heat integration is larger than that used with heating integration due to the heat recovery. The energy requirement is also taken into account in this work and shown in Table 4. It has been noted that the energy saving obtained here is about $48 \%$ compared with those without heat integration. Such result gives a clear indication that the $\mathrm{CO}_{2}$ emissions will be reduced by $48 \%$, which has the added benefit of significantly reducing environmental impact.

\section{The performance of an industrial FCC reactor}

Fluidized catalytic cracking is considered one of the most significant operations where the large molecules (undesirable compound) are converted into more valuable compounds leading to achieve the market request via increasing the middle distillates yields [particularly car fuel (gasoline) and diesel fuel (light cycle oil)] in addition to light gases obtained by this process. Therefore, an increase in productivity of such cuts is considered a major issue in the FCC operations and plays a significant role in coping with these issues.

After obtaining the optimal kinetic parameters, the maximum conversion, maximum RON, minimum coke deposited and optimal operating conditions as recently reported [7] and continuing with the present work by employing the whole results obtained, Fig. 8 illustrates the product yield (productivity) of an industrial fluidized catalytic cracking process using VGO as a feedstock. Based on the results presented in this figure, it is clearly observed that the productivity of valuable products (mainly gasoline and diesel fuel) increased utilizing the optimal data obtained while VGO content decreased. This increase in the productivity of valuable products can be attributed to conversion of vacuum gas oil compounds and long molecules that are concentrated in this cut (VGO) to light compounds (GLN, LCO, LPG, DG) owing to catalytic cracking reactions in such fluidized reactor.

\section{Conclusions}

Process of heat integration of the FCC unit was investigated to recover most of the external energy and reducing
Table 4 Optimization results for heat integration system

\begin{tabular}{lllll}
\hline Variables & $\begin{array}{l}\text { Without heating } \\
\text { integration }\end{array}$ & With heating integration & Decision variable type & Optimized value \\
\hline$A_{t}\left(\mathrm{~m}^{2}\right)$ & 15.852884 & 68.744644 & $T_{\mathrm{Out}, 1}\left({ }^{\circ} \mathrm{C}\right)$ & 231.22226 \\
$C_{t}(\$ / \mathrm{year})$ & $2.42532704 \mathrm{E} 8$ & $1.57962688 \mathrm{E} 8$ & $T_{\mathrm{Out}, 3}\left({ }^{\circ} \mathrm{C}\right)$ & 125.18642 \\
$m_{w}(\mathrm{~kg} / \mathrm{hr})$ & 1928.32956 & 1806.57972 & $T_{\mathrm{w} 1}\left({ }^{\circ} \mathrm{C}\right)$ & 115.0 \\
$C_{s}(\%)$ & - & 34.87 & $T_{\mathrm{w} 2}\left({ }^{\circ} \mathrm{C}\right)$ & 120 \\
$Q 1_{\mathrm{VGO}}(\mathrm{W})$ & - & 67098.45 & $T_{\mathrm{F} 1}\left({ }^{\circ} \mathrm{C}\right)$ & 28 \\
$Q 2_{\mathrm{VGO}}(\mathrm{W})$ & - & 43591.605 & $T_{\mathrm{F}}{ }^{*}\left({ }^{\circ} \mathrm{C}\right)$ & - \\
$Q 3_{w}(\mathrm{~W})$ & - & 138432.78 & - & - \\
$Q 4 w(\mathrm{~W})$ & - & 85681.945 & - & - \\
$Q$ & 3453183.5 & - & - \\
$\mathrm{ES}(\%)$ & - & 48 & - & \\
\hline
\end{tabular}


Fig. 8 Product yield of an industrial FCC reactions obtained in this work

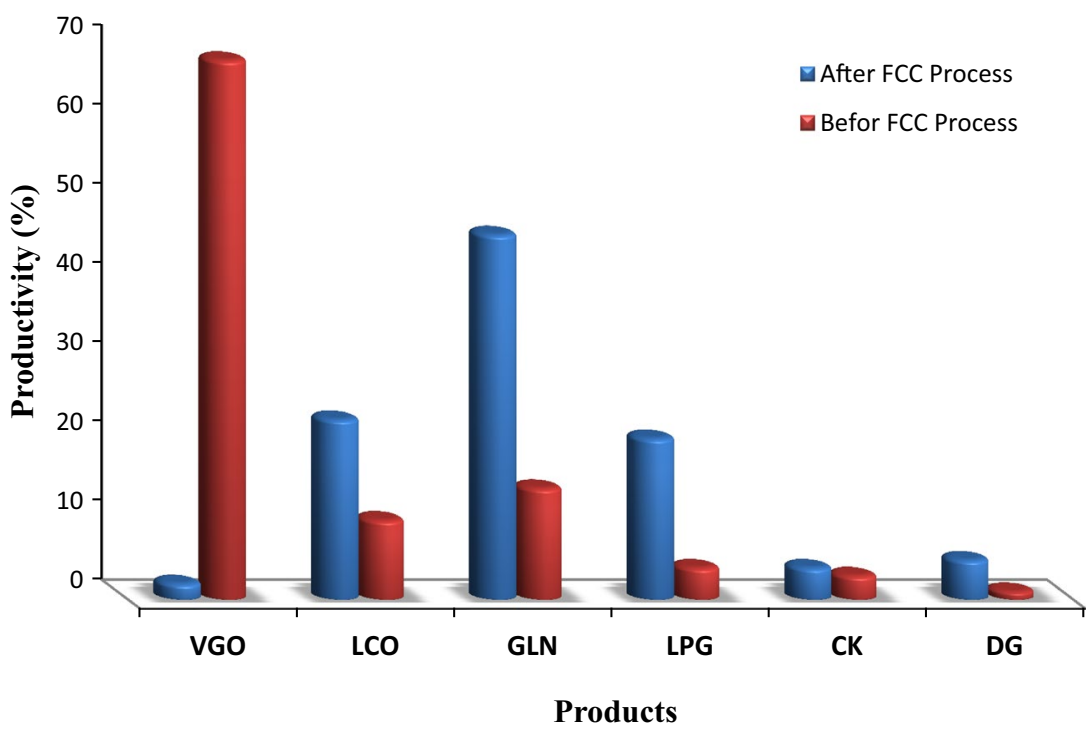

the environmental effect in addition to maximizing the productivity with minimum cost of the process. The energy recovery by heat integration between hot and cold streams from a large-scale fluidized catalytic cracking process was investigated and optimized. The energy consumption and heat recovery process was performed based on experimental information from pilot scale, mathematical modeling and commercial process and the minimum energy requirement and heat recovery were optimized. It was found that the heat integration process is very useful and efficient in commercial processes which maximizes production with minimum cost of the process. The cost savings and energy savings have been calculated to be $35 \%$ and $48 \%$, respectively, in comparison with the process of without heat integration. Also, applying the optimal results obtained, the yield of product of fluidized catalytic cracking processes has clearly been increased.

Open Access This article is distributed under the terms of the Creative Commons Attribution 4.0 International License (http://creativeco mmons.org/licenses/by/4.0/), which permits unrestricted use, distribution, and reproduction in any medium, provided you give appropriate credit to the original author(s) and the source, provide a link to the Creative Commons license, and indicate if changes were made.

\section{References}

1. Ahmed MA, Jarullah AT, Fayadh MA, Mujtaba IM (2018) Modelling of an industrial naphtha isomerization reactor and development and assessment of a new isomerization process. Chem Eng Res Des 137:33-46

2. Ashaibani AS, Mujtaba IM (2007) Minimisation of fuel energy wastage by improved heat exchanger network design: an industrial case study. Asia-Pac J Chem Eng 2:575-584

3. Bahakim SS, Ricardez-Sandoval LA (2015) Optimal design of a post combustion $\mathrm{CO}_{2}$ capture pilot-scale plant under process uncertainty: a ranking-based approach. Ind Eng Chem Res 54:3879-3892

4. Bouton GR, Luyben WL (2008) Optimum economic design and control of a gas permeation membrane coupled with the hydrotreating (HAD) Process. Ind Eng Chem Res 47:1221-1237

5. Douglas JM (1988) Conceptual design chemical processes. McGraw- Hill, New York

6. EPA (2015) United State Environmental Protection Agency, (www.epa.gov/tri)

7. Jarullah AT, Noor AA, Mujtaba IM (2017) Optimal design and operation of an industrial fluidized catalytic cracking reactor. Fuel 206:657-674

8. Jarullah AT (2011) Kinetic modeling simulation and optimal operation of trickle bed reactor for hydrotreating of crude oil, Ph.D. Thesis, University of Bradford

9. Jarullah AT, Mujtaba IM, Wood AS (2011) Modelling and optimization of crude oil hydrotreating process in trickle bed reactor: energy consumption and recovery issues. Chem Prod Process Model 2:1-19

10. Jarullah AT (2018) Modelling and simulation of a fluidized bed reactor for minimum ammonium nitrate and reduction of $\mathrm{NOx}$ emissions. Chem Eng Res Bull 20:8-18

11. Linnhoff B, Flower JR (1978) Synthesis of heat exchanger networks: II. Evolutionary generation of networks with various criteria of optimality. Am Inst Chem Eng J 24:642-654

12. Mohammed AE, Jarullah AT, Ghani SA, Mujtaba IM (2017) Significant cost and energy savings by heat integration in industrial three phase reactor for phenol oxidation. Comput Chem Eng 104:201-210

13. Khalfalla H (2009) Modelling and optimization of oxidative desulfurization process for model sulphur compounds and heavy gas oil, Ph.D. thesis, UK: University of Bradford

14. Smith R (2005) Chemical process design and integration. Wiley, Hoboken

15. Sinnott RK (2005) Chemical engineering, volume 6 chemical engineering design, 4th edn. Elsevier Butterworth-Heinemann, Amsterdam

16. Xiong K, Lu C, Wang Z, Gao X (2015) Kinetic study of catalytic cracking of heavy oil over an in situ crystallized FCC catalyst. Fuel 142:65-72

Publisher's Note Springer Nature remains neutral with regard to jurisdictional claims in published maps and institutional affiliations.

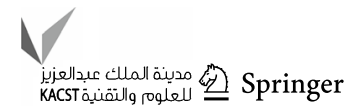

